\title{
Association of newly identified genetic variant rs2853677 of TERT with non-small cell lung cancer and leukemia in population of Jammu and Kashmir, India
}

Gh. Rasool Bhat ${ }^{1 \dagger}$, Amrita Bhat ${ }^{1 \dagger}$, Sonali Verma ${ }^{1}$, Itty Sethi ${ }^{2}$, Ruchi Shah², Varun Sharma ${ }^{2}$, Khursheed A. Dar ${ }^{3}$, Deepak Abrol ${ }^{4}$, Subiya Kaneez ${ }^{5}$, Sandeep Kaul ${ }^{6}$, Ramesh Ganju ${ }^{7}$ and Rakesh Kumar ${ }^{1 *}$

\begin{abstract}
Background: Telomere genetics has recently been emerged as an important field in molecular oncology. Various genome-wide association studies in different population groups have revealed that polymorphisms in Telomere maintenance gene (TERT) gene located on 5p15.33 is associated with susceptibility to leukemia and lung cancer risk. However, association of TERT with leukemia and lung cancer risk in north Indian population groups is still unknown. This study observed the association between genetic variant rs2853677 of TERT and leukemia and lung cancer in the state of Jammu and Kashmir, India.

Methods: A total of 781 subjects, out of which 381 cases (203 leukemic patients and 178 non-small cell lung cancer patients NSCLC) and 400 healthy controls were recruited for the study. Genetic variant rs2853677of TERT was detected using the real-time and Taqman Chemistry. Hardy-Weinberg Equilibrium was assessed using the chi square test. The allele and genotype- specific risks were estimated as odds ratio with 95\% confidence interval.

Results: We observed that variant rs 2853677 was strongly associated with lung cancer and leukemia risk with an odds ratio $(\mathrm{OR})=1.8(1.03-3.2$ at 95\% Cl); $p$ value (adjusted) $=0.03$; odds ratio $(\mathrm{OR})=2.9(1.4-5.5$.at 95\% Cl); $\mathrm{p}$ value (adjusted) $=0.002$, respectively.

Conclusion: The results of this study suggested that rs 2853677 of TERT signifies association in multiple cancers and suggests that it can become potential marker for diagnosis of non-small cell lung cancer and leukemia. The study will provide an insight in understanding the genetic etiology and highlights the role of telomere-associated pathways in non-small cell lung cancer and leukemia. However, it would be quite interesting to explore the contribution of this variant in other cancers as well.
\end{abstract}

Keywords: Non-small cell lung cancer, Leukemia, Telomerase reverse transcriptase (TERT), Jammu and Kashmir

\section{Background}

Lung cancer has highest mortality rate among cancers for both males and females, whereas males are more affected than females in leukemia by the ratio 1:5:1:0 [1]. Both the cancers are aggressive in nature, and this is one of the major global health concern worldwide. Lung cancer

\footnotetext{
* Correspondence: kumar.rakesh@smvdu.ac.in

${ }^{\dagger}$ Gh. Rasool Bhat and Amrita Bhat contributed equally to this work.

${ }^{1}$ Cancer Genetics Research Group, School of Biotechnology, Shri Mata

Vaishno Devi University, Katra, India

Full list of author information is available at the end of the article
}

constitutes $12.9 \%$ of all newly diagnosed cancer cases and $19.4 \%$ of all cancer associated deaths globally $[2,3]$ took place. Lung Cancer is the major cause of cancer related deaths in India accounting for 63,000 newly diagnosed patients each year with 52,000 deaths, and thereby contributing to $9.3 \%$ of all cancer associated deaths $[4,5]$. Furthermore, lung cancer in Kashmir region (J\&K) was reported to be the second most common malignancy in hospital based study. [6]. While in Jammu region (J\&K), unpublished data from our research group found that lung

(c) The Author(s). 2019 Open Access This article is distributed under the terms of the Creative Commons Attribution 4.0 International License (http://creativecommons.org/licenses/by/4.0/), which permits unrestricted use, distribution, and reproduction in any medium, provided you give appropriate credit to the original author(s) and the source, provide a link to the Creative Commons license, and indicate if changes were made. The Creative Commons Public Domain Dedication waiver (http://creativecommons.org/publicdomain/zero/1.0/) applies to the data made available in this article, unless otherwise stated. 
cancer and breast cancer are most commonly occurring cancers followed by esophageal cancer.

Lung cancer and Leukemia are multifactorial in nature, where both genetic and non-genetic factors like environmental pollution, occupational exposure and smoking mainly contribute to its etiology [7]. Single nucleotide polymorphism (SNP) genotyping and Genome wide association studies (GWAS) in Japanese population have revealed that chromosome $5 \mathrm{p} 15.33$ is the strong candidate region associated with lung cancer [8]. Genetic variant rs2853677 of telomere maintenance gene TERT is located in an intronic region of chromosome 5p15.33 (chr5:1,253,147-1,295,069) [9]. Telomeres are actually caps located at the terminal end of the linear chromosomes, which acts as an important factor in maintaining the genomic stability. In humans, telomeres comprise of guanine rich hexa nucleotide (TTAG GG) repeats. The stability of the telomeres solely depends on the integrity of the associated telomere maintenance proteins, which always work in coordinated manner, referred to as the shelterin complex [10]. Shelterin complex comprises of different factors like Telomeric Repeat Binding Factor 1 (TRF1), Telomeric Repeat Binding Factor 2 (TRF2), TRF1-Interacting Nuclear Factor 2 (TIN2), Protection of Telomeres 1 (POT1), Tripeptidyl Peptidase 1 (TPP1) and Repressor Activator Protein 1 (RAP1) [11]. Among the binding factors TRF1 and TRF2 bind to the double stranded telomeric DNA segment as homodimers. TRF1 inhibits the action of telomerase thus acts as negative regulator of telomere length [12] and the stability of T loop is maintained by TRF2. Mutation in TRF2 results in the activation of Ataxia Telangiectasia Mutated (ATM) protein mediated DNA damage signal which leads to end-to-end telomere fusion and telomere homologous recombination, leading to typical process of telomere sister-chromatid exchange (T-SCE) [13]. However, repressor activator protein 1 (RAP1) directly binds to TRF2 protein which is crucial for efficient binding of TRF2 protein to the telomeric DNA. Another important factor POT1 protects the chromosome ends from fusion and a typical recombination and helps in the recruitment of telomerase to the telomeric DNA, thus contributing to the protection of telomeres [14]. TRF-interacting nuclear factor 2 (TIN2) protein mainly binds with other shelterin proteins like TRF1, TRF2 and TPP1, acting as a critical component of the shelterin complex and bridging all these proteins of the shelterin complex together for efficient working. [12]. Shelterin proteins possibly regulate telomere elongation by enrolling Telomerase, which is a ribonucleoprotein complex consisting of reverse transcriptase (TERT) and RNA subunit (TERC). Telomerase is inactive and suppressed in most of the normal somatic cells. During the $\mathrm{S}$ phase of cell cycle, it gets activated and stimulates the replication process of telomeric DNA, which is not replicated, by DNA polymerase during replication [15].
Molecular alterations in the TERT promoter lead to enhanced expression of telomerase, which maintains telomere length thereby letting the cancer cells to continuously proliferate and inhibiting the programmed cell death and apoptosis [16].

In the present study, we conducted an association study of variant rs2853677 of TERT gene and susceptibility to non-small cell lung carcinoma and leukemia in population of Jammu and Kashmir. The critical reason to identify these associations is to understand the genetic heterogeneity of non-small cell lung cancer and leukemia and possibility of using the newly identified genetic variant of telomere maintenance gene (TERT) as prognostic biomarker for diagnosis of non-small cell lung cancer and leukemia.

\section{Methods}

\section{Ethical statement}

The study was approved by the Institutional Ethics Review board (IERB) of Shri Mata Vaishno Devi University (SMVDU) vide IERB Serial No: SMVDU/IERB/16/41 and SMVDU/IERB/16/47. The written consent were taken into account from each participant and all the parameters were recorded in pre-designed Performa.

\section{Sampling}

A total of 781 subjects, out of which 381 Cases (203 leukemic patients and 178 non-small cell lung cancer patients) and 400 healthy controls were recruited for study. All cancer cases were histopathologically confirmed. The genomic DNA was isolated from the blood samples using Qiagen DNA Isolation Kit (Catalogue No. 51206). Agarose gel electrophoresis was used to analyze the quality of genomic DNA and quantification was performed using UV spectrophotometer (Nanodrop).

\section{Genotyping}

Genotyping of variant rs2853677 was performed using allele discrimination assay on MX3005p Agilent Real time PCR platform. Taqman Probe labelled with VIC and FAM (Thermofisher Scientific) and UNG Master Mix (Applied Biosystems, USA) were used for genotyping.

Dilutions of assay were made from 40X concentration to 20X using TE (Tris EDTA buffer) as per recommendations of manufacturer. The Volume of total PCR reaction was $10 \mu \mathrm{l}$, comprising of $2.5 \mu \mathrm{l}$ of Taqman UNG Master Mix, $0.25 \mu \mathrm{l}$ of probe, $3 \mu \mathrm{l}$ DNA $(5 \mathrm{ng} / \mu \mathrm{l})$ and $4.25 \mu \mathrm{l}$ nuclease free water was added to make up the final volume. The Following thermal conditions were adopted; hold for $10 \mathrm{~min}$ at $95^{\circ} \mathrm{C}$, then 40 cycles of $95^{\circ} \mathrm{C}$ for $15 \mathrm{~s}$ and $60^{\circ} \mathrm{C}$ for $1 \mathrm{~min}$. All the samples were run in 96-well plate with three no template Control (NTC). The post PCR detection system is used to measure allele specific fluorescence. 93 random samples were picked 
Table 1 Showing Clinical Characteristics of Cases and Controls in non-small cell lung cancer and Leukemia

\begin{tabular}{|c|c|c|c|}
\hline Characteristics & Cases NSCLC $(n=178)$ & Cases Leukemia $(n=203)$ & Control $(n=400)$ \\
\hline 1. Age* (in years) & $61.07 \pm 9.65$ & $40.5( \pm 14.67)$ & $54.53 \pm 11.9$ \\
\hline \multirow[t]{2}{*}{ 2. Gender (in \% and No. of Cases) } & $M=80(n=143)$ & $M=60.6(n=123)$ & $M=70(n=280)$ \\
\hline & $\mathrm{F}=20(n=35)$ & $\mathrm{F}=39.3(n=80)$ & $\mathrm{F}=30(n=120)$ \\
\hline 3. $\mathrm{BMl}^{* *}$ & $22.4 \pm 3.89$ & $21.2( \pm 6.08)$ & $24.37 \pm 4.85$ \\
\hline 4. Histological Subtypes & $\begin{array}{l}\text { AC 0.63(n=112) } \\
\text { SCC 0.33(n=59) } \\
\text { UDC } 0.04(n=7)\end{array}$ & $\begin{array}{l}\text { ALL 0.17(n=35) } \\
\text { AML } 0.19(n=39) \\
\text { CML } 0.49(n=99) \\
\text { CLL 0.14(n=28) } \\
\text { MDS 0.01(n=2) }\end{array}$ & $\begin{array}{l}- \\
- \\
- \\
-\end{array}$ \\
\hline \multicolumn{4}{|l|}{ 5. Smoking (\% \& No. of Cases) } \\
\hline Yes & $82(n=146)$ & $56.3(n=114)$ & $18(n=72)$ \\
\hline No & $18(n=32)$ & $43.7(n=89)$ & $82(n=328)$ \\
\hline \multicolumn{4}{|l|}{ 6. Alcohol (\% and No. of Cases) } \\
\hline Yes & $37(n=66)$ & $6(n=12)$ & $12.5(n=50)$ \\
\hline No & $63(n=112)$ & $94(n=191)$ & $87.5(n=350)$ \\
\hline \multicolumn{4}{|l|}{ Guthka (\% and No. of Cases) } \\
\hline Yes & $9(n=16)$ & - & $6(n=24)$ \\
\hline No & $91(n=162)$ & - & $94(n=376)$ \\
\hline
\end{tabular}

*age in years and ${ }^{* *} \mathrm{BMl}$ in $\mathrm{kg} / \mathrm{m}^{2}$

and re-genotyped for cross validation of genotyping calls and the concordance rate was $100 \%$.

\section{Statistical analysis}

Statistical analysis of the data were completed with the application of SPSS software (v.20; Chicago, IL. Chi square test $\left(\chi^{2}\right)$ was performed and genotypic frequencies were tested for total Hardy-Weinberg equilibrium. Logistic regression was used to estimate OR at $95 \%$ confidence interval (CI) and respective level of significance as $p$ value.

\section{Results}

In the present case control association study, we made an attempt to replicate the novel genetic variant rs2853677 of TERT in the population of Jammu and Kashmir. The change in the nucleotide is g.1287079G > A. The clinical characteristic distribution of the cases and controls in non-small cell lung cancer and leukemia are given in Table 1. We used common control set for non-small cell lung cancer and leukemia in which 70\% were males and $30 \%$ were females. In non-small cell lung cancer cases $80 \%$ were males and $20 \%$ were females while in leukemia cases, $60.7 \%$ were males and $39.3 \%$ were females, stating the prevalence of both the cancers are high among males in the Jammu and Kashmir region. The mean ages for control set were $54.53( \pm 11.9)$ years, for the non-small cell lung cancer cases were $61.07( \pm 9.65)$ years and for the leukemia cases were 40.5 $( \pm 14.67)$ years.

In the current study allele $\mathrm{G}$ is being present more in cases (0.60 (NSCLC); 0.71 (Leukemia)) than in controls (0.53), hence, suggesting that allele $\mathrm{G}$ is causing risk. The allele frequency distribution has been summarized in Table 2 and Table 3 for non-small cell lung cancer and leukemia respectively. We observed that genetic allele G of variant rs 2853677 of TERT is significantly associated with non-small cell lung cancer $(p$ value $=0.03$ ) and leukemia ( $\mathrm{p}$ value $=2.6 \times 10^{-9}$ ) in the population of Jammu and Kashmir. To observe the maximum effect of allele G, we evaluated the association by using dominant model. The OR observed was $1.8(1.03-3.2)$ at 95\% CI in non-small cell lung cancer and $2.9(1.5-5.7)$ at $95 \% \mathrm{CI}$ in leukemia corrected for age, gender and BMI.

Furthermore, we have evaluated the variant rs2853677 of TERT gene by applying other genetic models as per the risk allele and the results observed were showing positive association of variant in all the three models in case of Leukemia Table 4 and only dominant was found to be associated with non-small cell lung cancer Table 5 .

Table 2 Allelic frequency distribution and risk associated with the TERT variation in non-small cell lung cancer in Jammu and Kashmir Population

\begin{tabular}{llccccccc}
\hline GENE/SNP & R.A & Cases $(n=178)$ & Controls $(n=400)$ & HWE & Allelic OR & $p$ Value & Dominant OR* $^{*} p$ value* \\
\hline TERT/rs2853677 & G & 0.60 & 0.53 & 0.261 & $1.3[1.02-1.7]$ & 0.03 & $1.8[1.03-3.2]$ & 0.03 \\
\hline
\end{tabular}

*Corrected for age, gender and BMI 
Table 3 Allelic frequency distribution and risk associated with the TERT variation in leukemia in Jammu and Kashmir Population

\begin{tabular}{llccllllr}
\hline GENE/SNP & R.A & Cases $(n=203)$ & Controls $(n=400)$ & HWE & Allelic OR & $p$ Value & Dominant OR $^{*}$ & $p$ value* \\
\hline TERT/rs2853677 & G & 0.71 & 0.53 & 0.654 & $2.2[1.6-2.8]$ & $2.6 \times 10^{-9}$ & $2.7[1.4-5.2]$ & 0.002 \\
\hline
\end{tabular}

*Corrected for age, gender and BMI

Smoking, being the primary agent in the etiology of lung cancer in more than $85 \%$ of cases. We explored the association of variant rs2853677 of TERT gene with smokers only. We selected only those individuals who had history of smoking from more than ten years to check its effect on LC (cases: 147; controls: 70; allelic distribution in Additional file 2: Table S2). The odds ratio observed was $2.4(1.5-5.2)$ at $95 \%$ CI. $p$ value $=0.02$. Thus, our finding indicates that the risk of variant rs2853677of TERT gene was higher in smokers than pooled population (smokers + non-smokers). Furthermore, in order to evaluate the effect of this genetic variant on TERT gene using insilco analysis by Human Splicing finder (HSF) [17]. It was observed that exonic splicing enhancer (ESE) site got broken. The majority of the algorithms used for the prediction of enhancer/silencer motifs by HSF (v.3.1) tool as described in Tables 6 and 7 indicated that rs 2853677 results in the broken sites for SF2/ASF (IgM-BRCA1) and creation of new binding sites of (serine/arginine rich protein) SRp55 (76.04), SC35 (78.30). Potential splice site in the variation region of TERTc.1574-4455 $\mathrm{C}>\mathrm{T}$ were described in (Fig. 1), green color depicts potential reference branch point and red color indicates potential mutant branch point, grey color for potential branch point (common to reference and mutant).

\section{Discussion}

Genomic wide association studies (GWAS) and candidate gene approach (CGA) have proven to be important tools in understanding genetic complexity and heterogeneity of these multifactorial diseases through case-control association in various ethnic groups. Therefore, this study investigated the association between TERT gene polymorphism and lung cancer and leukemia risk in the less explored population of Jammu and Kashmir of North India. We observed that variant rs2853677 was strongly associated with non-small cell lung cancer and leukemia risk with odds ratio (OR) $=1.8(1.03-3.2$ at $95 \% \mathrm{CI}) ; \mathrm{p}$ value (adjusted) $=0.03$ in

Table 4 showing the association of variant rs2853677 of TERT with leukemia in Jammu and Kashmir Population using different genetic models

\begin{tabular}{lllll}
\hline Genetic Model & Genotype & Odds Ratio & $95 \% \mathrm{Cl}$ & $p$ Value \\
\hline Dominant & GG/AG vs AA & 2.9 & $1.65-5.56$ & 0.001 \\
Additive & - & 1.9 & $1.41-2.66$ & 0.0001 \\
Recessive & GG/AA vs GG & 2.1 & $1.40-3.221$ & 0.0003 \\
\hline
\end{tabular}

*Corrected for Age, Gender and BMI
NSCLC and 2.7 (1.4-5.2 at 95\% CI); $p$ value (adjusted) $=0.002$ in leukemia, signifying that TERT polymorphism plays a crucial role in the pathological process of multiple cancers. Our findings are consistent with previous genome wide association studies stating the role of TERT gene in different cancers at different ethnicities $[8,18-22]$. Furthermore it was observed that the subtype adenocarcinoma (AC) and squamous cell carcinoma (SCC) of non-small cell lung cancer was found to be associated with odds ratio $\mathrm{OR}=1.37$ and 1.50 respectively whereas, the subtype undifferentiated carcinoma (UDC) was not significantly associated. The possible reason being small sample size $(n=7)$ However in leukemia, the subtypes Acute Lymphoblastic Leukemia (ALL), Acute Myeloid Leukemia (AML),Chronic Myeloid Leukemia (CML), Chronic Lymphoid Leukemia (CLL) were found to be associated with an $\mathrm{OR}=1.75,1.71,1.40,1.81$ respectively. Myelodysplastic Syndrome (MDS) subtype of leukemia did not show any association with possible reason of small sample size. Additional file 1: Table S1.

Human Pulmonary neoplasms and leukemia's are heterogeneous in nature, wherein both genetic and non-genetic factors like smoking mainly contribute to its etiology [7]. Jammu and Kashmir is Lung cancer capital of India and Tobacco sales are at highest peak. However, the genetic susceptibility to lung cancer and leukemia is still unclear; the accumulation of low risk alleles may result in inherited risk. Genetic variant rs2853677 of telomere maintenance gene TERT is located in intronic region of chromosome 5p15.33. Molecular alteration (polymorphism) in telomere maintenance genes results in destabilization of shelterin complex which could lead to constitutive activation of ribonucleoprotein complex like TERT (Fig. 2). The overexpression of TERT results in maintenance of telomere length resulting in cell immortality and allows the progression of a preneoplastic lesion towards malignant stages. So these polymorphisms might prove to be a prognostic or predictive biomarker in population group under study.

Table $\mathbf{5}$ showing the association of variant rs2853677 of TERT with non- small cell lung cancer in Jammu and Kashmir Population using different genetic models

\begin{tabular}{lllll}
\hline Genetic Model & Genotype & Odds Ratio & $95 \% \mathrm{Cl}$ & $p$ Value \\
\hline Dominant & GG/AG vs AA & 1.8 & $1.03-3.19$ & 0.03 \\
Additive & - & 1.4 & $1.00-2.09$ & 0.05 \\
Recessive & GG/AA vs GG & 1.2 & $0.82-3.19$ & .279 \\
\hline *Corrected for Age, Gender and BMI & & &
\end{tabular}

*Corrected for Age, Gender and BMI 
Table 6 Representation of Potential Alteration of Splicing site by HSF (v.3.1)

\begin{tabular}{|c|c|c|c|}
\hline Predicted signal & Prediction algorithm & cDNA Position & Interpretation \\
\hline New Donor Site & 1 - HSF Matrices & $\frac{g-g \text { a c c c g-c.tg-g-t g }}{\frac{1}{462-4,460-4,458-4,456-4,454-4,452-4,450-4,4}}$ & $\begin{array}{l}\text { Activation of an intronic } \\
\text { cryptic donor site. } \\
\text { Potential alteration of splicing }\end{array}$ \\
\hline
\end{tabular}

Table7: In silico Analysis of the SNP rs2385677 by Human Spicing Finder (v.3.1).

\begin{tabular}{|c|c|c|c|c|}
\hline Method & Motif G/C Allele & Motif A/T Allele & Threshold Value & Result \\
\hline \multirow[t]{3}{*}{ ESE Finder } & $\operatorname{ccgcctg}(71.23)$ & - & - & $\begin{array}{c}\text { SF2/ASF (IgM- } \\
\text { BRCA1) site } \\
\text { broken }\end{array}$ \\
\hline & - & gacccgtc (78.30) & 75.05 & $\begin{array}{c}\text { New SC35 binding } \\
\text { Site }\end{array}$ \\
\hline & - & cccgtc (76.04) & 73.86 & $\begin{array}{l}\text { New SRp55 binding } \\
\text { site }\end{array}$ \\
\hline \multirow[t]{6}{*}{ EIEs (Zhang et al) } & Acccgc & \multirow[t]{6}{*}{-} & \multirow[t]{6}{*}{-} & \multirow[t]{6}{*}{ Site broken } \\
\hline & Cccgcc & & & \\
\hline & Ccgect & & & \\
\hline & Cgcctg & & & \\
\hline & Gcctgg & & & \\
\hline & Cctggt & & & \\
\hline IEs from (Zhang et al) & - & gtctgg & - & New Site \\
\hline $\begin{array}{l}\text { Other Splicing motifs - } \\
\text { Exonic Splicing } \\
\text { Regulatory Sequences } \\
\text { (Goren et al) }\end{array}$ & $\begin{array}{l}\text { Cgcctg } \\
\text { Gcctgg }\end{array}$ & - & - & Site broken \\
\hline
\end{tabular}

In order to determine the effect of this SNP rs2385677 on the functioning of TERT gene, the bioinformatics in silico analysis of this variant was performed by HSF (v.3.1). It showed that the variant creates broken sites that could influence the physiology of TERT gene. Moreover, the splicing effect of the variant needs to be confirmed in-vitro analysis. Although we were not able to fully evaluate the stratified analysis in different subtypes of non-small cell lung cancer and leukemia due to less sample size in each sub type. We also take it as quest to evaluate these subtypes with large sample size in future course. The present study also provides an important information of the genetic etiology of non-small cell lung cancer and leukemia and strengthens clinical findings and highlighting the role of telomere maintenance genes in leukemia and lung cancer, which may have impact to clinical and public health data in population of Jammu and Kashmir. It is also taken into account to screen other telomere maintenance genes in other Indian ethnic groups targeting different cancers $[9,19,23,24]$. This variant has not been explored with lung cancer or leukemia in any other Indian population groups and this is the first study from the region. These findings could be potential conformations and could be used as potential predictive or prognostic markers in clinical studies of leukemia and lung cancer patients in J\&K population groups. 
Table 7 In silico Analysis of the SNP rs2385677 by Human Spicing Finder (v.3.1)

\begin{tabular}{|c|c|c|c|c|}
\hline Method & $\begin{array}{l}\text { Motif G/C } \\
\text { Allele }\end{array}$ & $\begin{array}{l}\text { Motif ATT } \\
\text { Allele }\end{array}$ & $\begin{array}{l}\text { Threshold } \\
\text { Value }\end{array}$ & Result \\
\hline \multirow[t]{3}{*}{ ESE Finder } & $\begin{array}{l}\text { ccgcctg } \\
(71.23)\end{array}$ & - & - & $\begin{array}{l}\text { SF2/ASF (IgM-BRCA1) site } \\
\text { broken }\end{array}$ \\
\hline & - & $\begin{array}{l}\text { gacccgtc } \\
(\mathbf{7 8 . 3 0})\end{array}$ & 75.05 & New SC35 binding Site \\
\hline & - & $\operatorname{cccgtc}(76.04)$ & 73.86 & New SRp55 binding site \\
\hline \multirow[t]{6}{*}{ ElEs (Zhang et al) } & Acccgc & - & - & Site broken \\
\hline & Cccgec & & & \\
\hline & Ccgcct & & & \\
\hline & Cgcctg & & & \\
\hline & Gcctgg & & & \\
\hline & Cctggt & & & \\
\hline IEs from (Zhang et al) & - & gtctgg & - & New Site \\
\hline $\begin{array}{l}\text { Other Splicing motifs - Exonic Splicing Regulatory Sequences } \\
\text { (Goren et al) }\end{array}$ & $\begin{array}{l}\text { Cgcctg } \\
\text { Gcctgg }\end{array}$ & - & - & Site broken \\
\hline
\end{tabular}

The values in bold represents the mutant motif threshold value which are higher than the reference motif threshold value indicating their possible role in the alteration of splicing factor binding sites and splicing sites

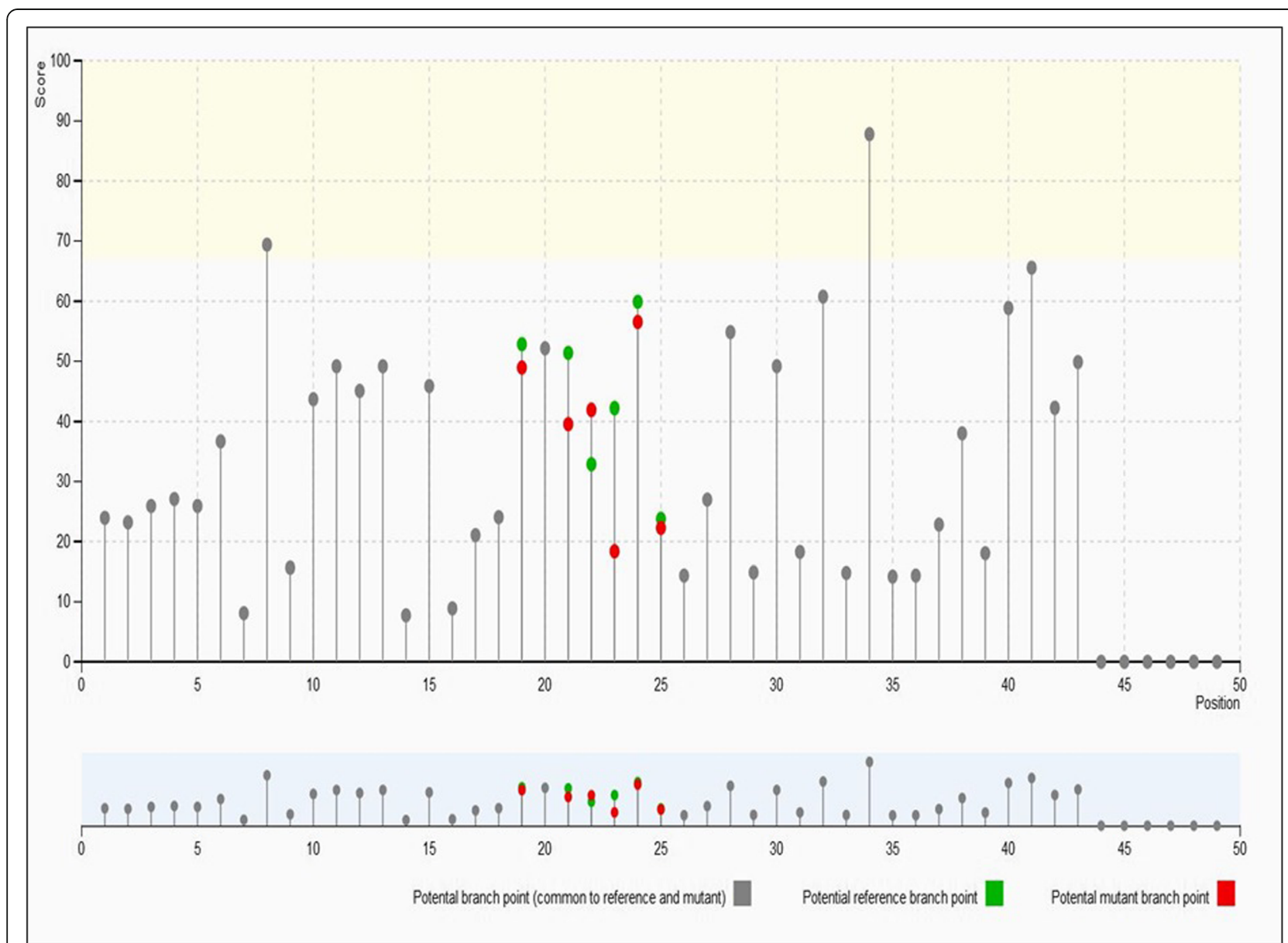

Fig. 1 Potential Splice sites in the variation region TERT c.1574-4455C > T. Potential splice site in the variation region of TERTC.1574-4455C > T were described in Fig. 1,whererin green color depicts potential reference branch point and red color indicates potential mutant branch point, grey color for potential branch point (common to reference and mutant) 


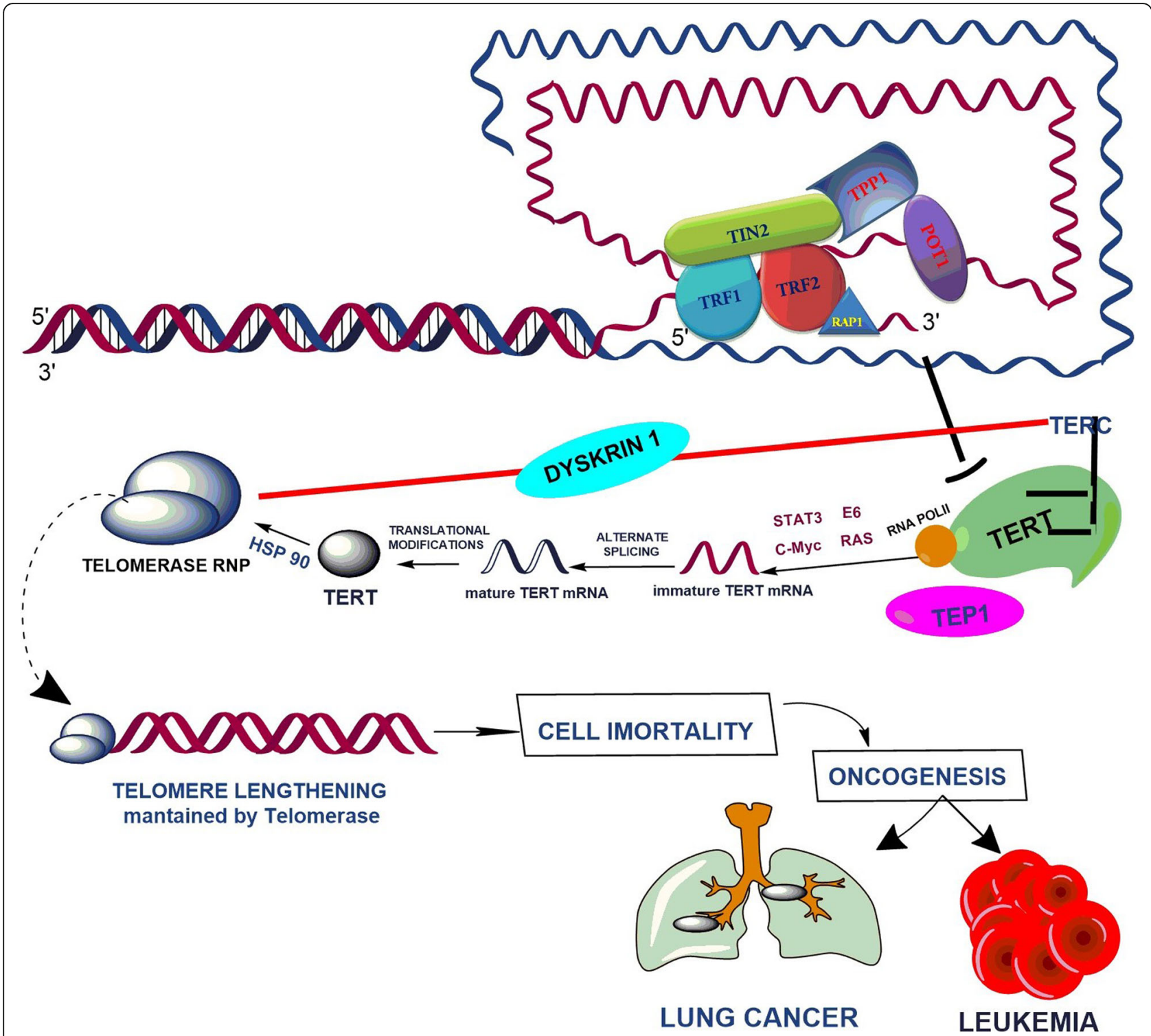

Fig. 2 Schematic representation of telomerase regulation and telomere elongation pathway. Molecular alteration leading to overexpression of TERT gene resulting in cell immortality and drive the cell for oncogenesis

\section{Conclusion}

We observed that the genetic variant rs2853677 in the TERT loci is linked with an increased non-small cell lung cancer and leukemia risk in Jammu and Kashmir (North Indian) population. Our result revealed the complex genetic regulation of telomere genetics and highlighted the critical role of telomere maintenance gene (TERT) in the pathogenesis of non-small cell lung cancer and leukemia. The limitations of the present study include, the sample size among the subtypes of non-small cell lung cancer and leukemia was relatively small. These findings may also enhance our understanding of inter-population differences in leukemia and lung cancer etiology and strengthens GWAS findings as well, although the physiological functions of these TERT SNPs need to be explored in others cancers in future study designs.

\section{Additional files}

Additional file 1: Table S1. Showing the genetic association of variant rs2853677 of TERT among the various subtypes of non-small cell lung cancer and leukemia. (DOCX $15 \mathrm{~kb}$ )

Additional file 2: Table S2. Allele frequency distribution and risk associated with smokers and non-small cell lung cancer. (DOCX 16 kb)

\section{Abbreviations}

GWAS: Genome wide association studies; HSF: Human Splicing finder; NSCLC: Non-small cell lung cancer; OR: Odds Ratio; SNP: Single nucleotide polymorphism; TERT: Telomerase reverse transcriptase 


\section{Acknowledgements}

All authors acknowledge all the participants for their contribution in this study and RK, GRB acknowledge Department of Science and Technology, Govt. of India for financial assistance.

\section{Funding}

Department of Science and Technology, Govt. of India for Grant (DST/SSTP/ J\&K/459). The role of the funding agency Department of Science TechnologyGovernment of India provided specific Non-small cell lung cancer grant (DST/ SSTP/J\&K/459) for the purchase of reagents/chemicals and the payment of fellowship to $G R$ and $A B$.

\section{Availability of data and materials}

All data generated and/or analyzed during this study are available from the corresponding author upon reasonable request.

\section{Authors contribution}

RK and GRB planned the work, GRB carried out work on non-small cell lung cancer samples and wrote the manuscript and restructured it, AB carried out work on leukemia samples SV, RS, helped in sampling processes, IS, VS contributed in data analysis, DA, SK2, KAD, SK1 gave technical suggestions, RG gave the expert technical suggestions and RK finally refined the manuscript. All authors finally revised and approved the manuscript.

\section{Ethics approval and consent to participate}

The study was approved by the Institutional Ethics Review board (IERB) of Shri Mata Vaishno Devi University (SMVDU) vide IERB Serial No: SMVDU/IERB/ $16 / 41$ and SMVDU/IERB/16/47. The consent form was designed in three languages (English, Hindi, Urdu) and an informed and written consent was taken from patient and control before the sample collection.

\section{Consent for publication}

Our manuscript does not contain any individual person's data in any form (including any individual details, images or videos).

\section{Competing interests}

The authors declare that they have no competing interests.

\section{Publisher's Note}

Springer Nature remains neutral with regard to jurisdictional claims in published maps and institutional affiliations.

\section{Author details}

${ }^{1}$ Cancer Genetics Research Group, School of Biotechnology, Shri Mata Vaishno Devi University, Katra, India. ${ }^{2}$ Human Genetics Research Group, School of Biotechnology, Shri Mata Vaishno Devi University, Katra, India. ${ }^{3}$ Chest Disease Hospital, Government Medical College, Srinagar, India. ${ }^{4}$ Department of Radiotherapy, Government Medical College, Jammu, India. ${ }^{5}$ Department of Radiotherapy, Government Medical College, Srinagar, India. ${ }^{6}$ Department of surgical Oncology, Shri Mata Vaishno Devi Narayana Super speciality hospital, kata, India. ${ }^{7}$ Department of Pathology, College of Medicine, The OHIO State University, Columbus, USA.

\section{Received: 20 July 2018 Accepted: 8 May 2019}

\section{Published online: 24 May 2019}

\section{References}

1. Asthana S, Labani S, Mehrana S, Bakhshi S. Incidence of childhood leukemia and lymphoma in India. Pediatric Hematology Oncology Journal. 2018.

2. Torre LA, Bray F, Siegel RL, Ferlay J, Lortet-Tieulent J, Jemal A. Global cancer statistics, 2012. CA Cancer J Clin. 2015;65(2):87-108.

3. Jemal A, Bray F, Center MM, Ferlay J, Ward E, Forman D. Global cancer statistics. CA Cancer J Clin. 2011;61(2):69-90.

4. Malik PS, Raina V. Lung cancer: prevalent trends \& emerging concepts. Indian J Med Res. 2015;141(1):5.

5. Ganesh B, Sushama S, Monika S, Suvarna P. A case-control study of risk factors for lung cancer in Mumbai India. Asian Pac J Cancer Prev. 2011;12(2): $357-62$

6. Dhar GM, Shah GN, Naheed B. Hafiza: epidemiological trend in the distribution of cancer in Kashmir Valley. J Epidemiol Community Health. 1993;47(4):290-2.
7. Shields PG. Molecular epidemiology of smoking and lung cancer. Oncogene. 2002;21(45):6870

8. Shiraishi K, Kunitoh H, Daigo Y, Takahashi A, Goto K, Sakamoto H, Ohnami S, Shimada Y, Ashikawa K, Saito A. A genome-wide association study identifies two new susceptibility loci for lung adenocarcinoma in the Japanese population. Nat Genet. 2012;44(8):900.

9. Karami S, Han Y, Pande M, Cheng I, Rudd J, Pierce BL, Nutter EL, Schumacher FR, Kote-Jarai Z, Lindstrom S. Telomere structure and maintenance gene variants and risk of five cancer types. Int J Cancer. 2016; 139(12):2655-70.

10. Sethi I, Bhat G, Singh V, Kumar R, Bhanwer A, Bamezai RN, Sharma S, Rai E. Role of telomeres and associated maintenance genes in type 2 diabetes mellitus: a review. Diabetes Res Clin Pract. 2016;122:92-100.

11. Choi KH, Farrell AS, Lakamp AS, Ouellette MM. Characterization of the DNA binding specificity of Shelterin complexes. Nucleic Acids Res. 2011;39(21): 9206-23.

12. Palm W, de Lange T. How shelterin protects mammalian telomeres. Annu Rev Genet. 2008;42:301-34.

13. De Lange T. Shelterin: the protein complex that shapes and safeguards human telomeres. Genes Dev. 2005;19(18):2100-10.

14. He Q, Zeng P, Tan J-H, Ou T-M, Gu L-Q, Huang Z-S, Li D. G-quadruplexmediated regulation of telomere binding protein POT1 gene expression. Biochimica et Biophysica Acta (BBA)-General Subjects. 2014;1840(7):2222-33.

15. Zhang Y, Chen L-Y, Han X, Xie W, Kim H, Yang D, Liu D, Songyang Z. Phosphorylation of TPP1 regulates cell cycle-dependent telomerase recruitment. Proc Natl Acad Sci. 2013;1 10(14):5457-62.

16. Griewank KG, Murali R, Schilling B, Schimming T, Möller I, Moll I, Schwamborn M, Sucker A, Zimmer L, Schadendorf D. TERT promoter mutations are frequent in cutaneous basal cell carcinoma and squamous cell carcinoma. PLoS One. 2013;8(11):e80354.

17. Desmet F-O, Hamroun D, Lalande M, Collod-Béroud G, Claustres M, Béroud C. Human splicing finder: an online bioinformatics tool to predict splicing signals. Nucleic Acids Res. 2009;37(9):e67.

18. Zanetti KA, Wang Z, Aldrich M, Amos Cl, Blot WJ, Bowman ED, Burdette L, Cai Q, Caporaso N, Chung CC. Genome-wide association study confirms lung cancer susceptibility loci on chromosomes 5p15 and 15q25 in an African-American population. Lung Cancer. 2016;98:33-42.

19. Ye G, Tan N, Meng C, Li J, Jing L, Yan M, Jin T, Chen F. Genetic variations in TERC and TERT genes are associated with lung cancer risk in a Chinese Han population. Oncotarget. 2017;8(66):110145.

20. Speedy HE, Di Bernardo MC, Sava GP, Dyer MJS, Holroyd A, Wang Y, Sunter NJ, Mansouri L, Juliusson G, Smedby KE, et al. A genome-wide association study identifies multiple susceptibility loci for chronic lymphocytic leukemia. Nat Genet. 2013:46:56

21. Calado RT, Regal JA, Hills M, Yewdell WT, Dalmazzo LF, Zago MA, Lansdorp PM, Hogge D, Chanock SJ, Estey EH, et al. Constitutional hypomorphic telomerase mutations in patients with acute myeloid leukemia. Proc Natl Acad Sci U S A. 2009;106(4):1187-92.

22. Wang $H$, Yang $H$, Feng $T$, Geng $T$, Chen $C$, Jin T. Effects of TERT gene polymorphism and environmental factor interactions on lung cancer risk in the Xi'an Han population. Int J Clin Exp Med. 2016;9:4200-10.

23. Di Bernardo MC, Crowther-Swanepoel D, Broderick P, Webb E, Sellick G, Wild R, Sullivan K, Vijayakrishnan J, Wang Y, Pittman AM. A genome-wide association study identifies six susceptibility loci for chronic lymphocytic leukemia. Nat Genet. 2008;40(10):1204.

24. Timofeeva MN, Hung RJ, Rafnar T, Christiani DC, Field JK, Bickeböller H, Risch A, McKay JD, Wang Y, Dai J. Influence of common genetic variation on lung cancer risk: meta-analysis of 14900 cases and 29485 controls. Hum Mol Genet. 2012;21(22):4980-95. 